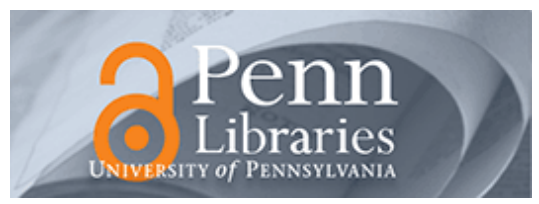

University of Pennsylvania

ScholarlyCommons

Operations, Information and Decisions Papers

Wharton Faculty Research

9-2009

\title{
Competing Retailers and Inventory: An Empirical Investigation of General Motors' Dealerships in Isolated U.S. Markets
}

Marcelo Olivares

Gerard. P. Cachon

University of Pennsylvania

Follow this and additional works at: https://repository.upenn.edu/oid_papers

Part of the Business Administration, Management, and Operations Commons, Marketing Commons, and the Operations and Supply Chain Management Commons

\section{Recommended Citation}

Olivares, M., \& Cachon, G. P. (2009). Competing Retailers and Inventory: An Empirical Investigation of General Motors' Dealerships in Isolated U.S. Markets. Management Science, 55 (9), 1586-1604.

http://dx.doi.org/10.1287/mnsc.1090.1050

This paper is posted at ScholarlyCommons. https://repository.upenn.edu/oid_papers/211

For more information, please contact repository@pobox.upenn.edu. 


\title{
Competing Retailers and Inventory: An Empirical Investigation of General Motors' Dealerships in Isolated U.S. Markets
}

\begin{abstract}
We study the following question: How does competition influence the inventory holdings of General Motors' dealerships operating in isolated U.S. markets? We wish to disentangle two mechanisms by which local competition influences a dealer's inventory: (1) the entry or exit of a competitor can change a retailer's demand (a sales effect); and (2) the entry or exit of a competitor can change the amount of buffer stock a retailer holds, which influences the probability that a consumer finds a desired product in stock (a service-level effect). Theory is clear on the sales effect-an increase in sales leads to an increase in inventory (albeit a less than proportional increase). However, theoretical models of inventory competition are ambiguous on the expected sign of the service-level effect. Via a Web crawler, we obtained data on inventory and sales for more than 200 dealerships over a six-month period. Using crosssectional variation, we estimated the effect of the number and type of local competitors on inventory holdings. We used several instrumental variables to control for the endogeneity of market entry decisions. Our results suggest that the service-level effect is strong, nonlinear, and positive. Hence, we observe that dealers carry more inventory (controlling for sales) when they face additional competition.
\end{abstract}

\section{Keywords}

inventory competition, empirical, entry, supply chain management, automobile industry

\section{Disciplines}

Business Administration, Management, and Operations | Marketing | Operations and Supply Chain Management 


\title{
Competing Retailers and Inventory: An Empirical Investigation of General Motors' Dealerships in Isolated U.S. Markets*
}

\author{
Marcelo Olivares · Gérard P. Cachon \\ Columbia Business School, Columbia University, New York NY, \\ molivares@columbia.edu \\ www.columbia.edu/ ${ }^{\sim}$ mo2338 \\ The Wharton School, University of Pennsylvania, Philadelphia PA, 19104 \\ cachon@wharton.upenn.edu \\ opim.wharton.upenn.edu $/ \sim$ cachon
}

June 4, 2007; Revised April 7, 2008, March 17, 2009, May 13, 2009

\section{Abstract}

We study the following question: how does competition influence the inventory holdings of General Motors' dealership operating in isolated U.S. markets? We wish to disentangle two mechanisms by which local competition influences a dealer's inventory: (1) the entry or exit of a competitor can change a retailer's demand (a sales effect); (2) the entry or exit of a competitor can change the amount of buffer stock a retailer holds, which influences the probability a consumer finds a desired product in stock (a service level effect). Theory is clear on the sales effect - an increase in sales leads to an increase in inventory (albeit a less than proportional increase). However, theoretical models of inventory competition are ambiguous on the expected sign of the service level effect. Via a web crawler, we obtained data on inventory and sales for more than 200 dealerships over a six month period. Using cross-sectional variation, we estimated the effect of the number and type of local competitors on inventory holdings. We used several instrumental variables to control for the endogeneity of market entry decisions. Our

${ }^{*}$ The authors thank Joel Waldfogel for his guidance and suggestions. We are grateful to Alan Abrahams, Michelle Gallert and Gabe Silvasi for their help in the implementation of the web-crawler. We thank the suggestions of seminar participants at Washington University, University of Maryland, University of North Carolina, New York University, Georgia Tech, Columbia, Harvard, University of Virginia, University of Texas at Austin, Stanford, INSEAD, University of Chicago, Northwestern University and UCLA. We also thank the Fishman-Davidson Center, The Wharton School, University of Pennsylvania, for financial support. A previous version of this paper was titled "Competing Retailers and Inventory: An Empirical Investigation of U.S. Automobile Dealerships." 
results suggest that the service level effect is strong, non-linear and positive. Hence, we observe that dealers carry more inventory (controlling for sales) when they face additional competition.

Keywords: Inventory competition, empirical, entry, supply chain management, automobile industry. 


\section{Introduction}

How does local competition influence a retailer's inventory holdings? Although an active theoretical literature has recently emerged to explore this question, the question has so far received no direct empirical investigation, which is the objective of this paper.

We focus on two mechanisms by which the degree of competition a retailer faces moderates the retailer's days-of-supply of inventory (i.e., the amount of inventory the retailer carries relative to its sales). First, competition has a sales effect - increased competition lowers a retailer's sales. Inventory theory (e.g., Zipkin (2000)) is clear on the direction of the sales effect: lower sales leads to a higher days-of-supply because of economies of scale in inventory management. Second, competition has a service level effect - increased competition influences the retailer's service level, which, roughly speaking, is the probability the retailer has in stock an item when a customer requests it. Here, theory is ambiguous. On the one hand, more competition leads to more intense price competition and lower margins, which suggests a lower service level is optimal. On the other hand, more competition gives consumers more choices for where and what to purchase, which suggests a higher service level is optimal so as to better retain demand. Therefore, two questions naturally emerge from this discussion: (1) can we empirically resolve the direction of the servicelevel effect and (2) how large is the service-level effect relative to the sales effect? If the service-level effect is positive (i.e., more competition leads to higher service levels) then these two effects are additive with respect to increased competition, which certainly leads to a higher days-of-supply. If the service-level effect is negative, then these two effects moderate each other and the net impact of competition on days-of-supply may be small (if their strengths are comparable).

We explore these issues in the context of the automobile industry. In particular, we collected daily inventory and sales data over a six month period from General Motors (GM) dealerships located in more than 200 markets within the United States. Our data, collected with a custom built web-crawler, enables us to track individual vehicles (via each vehicle's unique identification number, or VIN) as they were added to or removed from a dealership's inventory because of a sale to a consumer or a transfer between dealerships. We focus on isolated markets so that we can clearly identify the number of competitors (i.e., dealerships) in the same market and the type of competitors within the same market (i.e., the number of GM dealerships and the number of nonGM dealerships), but we provide some evidence that the dealers in our sample are representative of the entire population of GM dealers. 
Table 1 reports summary statistics from our data and illustrates the considerable heterogeneity in inventory holdings across brands and across dealerships within a brand. Our empirical strategy exploits this cross-sectional variation in the observed markets to identify the effects of interest. We use instrumental variables to control for the endogeneity of market entry decisions with respect to unobserved market characteristics. (For example, some markets could have more GM dealerships because GM is aware of certain market characteristics that make them favorable to GM dealerships and those unobserved characteristics may also influence inventory holdings in those markets.) We focus on the auto industry because it is economically significant and detailed data on local inventory holdings are available (via our web-crawler). Although our results are specific to this industry, our econometric methods could be applied to study inventory in other retail industries. Furthermore, some of our findings may apply broadly to other forms of retailing.

This research is related to the growing empirical literature on inventory. Wu et al. (2005) study the relationship between firm inventory holdings and financial performance, while Hendricks and $\underline{\text { Singhal (2005) }}$ study the impact of supply chain disruptions (including problems with inventory) on short term financial and accounting measures. Gaur et al. (2005a) find that as a retailer's margins decreases and capital intensity increases, it tends to carry less inventory relative to sales (i.e., days of supply). Rumyantsev and Netessine (2007) use aggregate inventory data to measure the relationship between demand uncertainty, lead times, gross margins and firm size on inventory levels. Rajagopalan (2005) estimates the effect of product variety on inventory levels of publicly listed U.S. retailers. Amihud and Mendelson (1989) use public data on manufacturing firms to estimate the effect of market power (proxied by the firms' margins and market shares) on inventory levels and variability. They find that firms lower their inventory as market power decreases, i.e., as competition intensifies. Cachon and Olivares (2006) study inventory in the auto industry at the brand level (e.g., Honda, Chevrolet) and report a positive association between the number of dealerships and inventory, among other factors that influence inventory. Note, all of these studies use aggregated inventory at a brand, company or industry level and either have no measure of competition or only an indirect measure of competition (e.g., observed margins or total number of dealerships). In contrast, this work has data on individual units of inventory and direct measures of the degree of competition in local markets.

In our work, a dealer's inventory service level is one measure of the quality of the service the dealer provides its customers - customers prefer higher service levels and a high service level is 
costly to the dealer. Therefore, our work is related to the considerable literature that empirically investigates the relationship between competition and the level of quality provided in a market. For example, Berry and Waldfogel (2003) compare two industries, local newspapers (where quality is measured by the amount of content and the number of reporters) and restaurants (where quality is measured through ratings). They find that competition decreases quality in the newspaper industry but increases quality with restaurants. Cohen and Mazzeo (2004) study retail banking, where quality is measured in terms of the number of branches a bank operates. As with newspapers, they find that higher competition leads to lower quality. Others use product variety as a measure of quality, such as Berry and Waldfogel (2001) with radio broadcasting, Alexander (1997) with music recording, Ellickson (2007) with supermarkets and hair cutting establishments (i.e., barber shops and salons), and Watson (2004) with eyeglass retailers. As in our paper, in each of those studies there exists competing theories regarding the relationship between competition and quality.

Section 3 describes the data and the specification of the model. Section 4 shows our main results and section 5 provides a sensitivity analysis and further empirical evidence. Section 6 measures the relative magnitude of the effects we identify and discusses the implication for adding and subtracting dealerships to local markets. We conclude and discuss our findings in section 7 .

\section{An empirical model of retail inventory}

In this section we use a basic inventory model to motivate a general empirical framework for the relationship between retail inventory and competition. In the subsequent sections we apply this framework to our analysis of inventory of vehicles at automobile dealerships.

Orders are received at the beginning of each period with zero lead-time. Let $D$ be i.i.d. normal demand in each period with mean $\mu$ and standard deviation $\sigma$. Some fraction of the demand that is not fulfilled from in-stock inventory is backordered; the remaining demand is lost. Each period inventory is ordered so that there are $Q$ units on-hand before demand occurs. In this model the service level is the probability that all demand within a period is satisfied from inventory. The service level is increasing in $z=(Q-\mu) / \sigma$, so for convenience we refer to $z$ as the service level with the understanding that it is really a proxy for the service level. The expected inventory at the end of each period, $I$, is then

$$
I=\sigma(z+L(z))
$$

where $L(z)$ is the standard normal loss function (see Zipkin (2000) for additional details). 
It is empirically inconvenient to work with (1) directly because demand is not observable. However, (1) can be written as

$$
I=\sigma_{s} K(z)
$$

(see the appendix for details) where $\sigma_{s}$ is the standard deviation of sales $(\min \{Q, D\})$ and $K(z)$ is an increasing function. As in van Ryzin and Mahajan (1999), we use

$$
\sigma_{s}=A \cdot S^{\beta_{s}}
$$

to approximate the standard deviation of sales, where $S$ is observed sales over a sample period and $A$ and $\beta_{s}$ are coefficients. The $\beta_{s}$ coefficient reflects the degree to which there are economies of scale in inventory management with respect to sales. ${ }^{1}$ If $\beta_{s}=1$, then days-of-supply (inventory divided by daily demand rate) is independent of expected sales whereas if $\beta_{s}<1$, then higher sales retailers carry a lower days-of-supply for the same service level. ${ }^{2}$ Combining (2) and (3) and taking logarithms yields:

$$
\log I=\text { constant }+\beta_{s} \log S+\log K(z)
$$

The above equation suggests that a firm's inventory level can be decomposed into two separate components: a sales component, $\beta_{s} \log S$, and a service level component, $\log K(z)$.

According to (4), competition can influence a firm's inventory through its sales or through its service level or through both. The meaning of "competition" can depend on the particular retail industry considered, but to provide concreteness to this discussion, we use the term "competition" to refer to the number and type of retailers in a market. For example, in the context of our data analysis, "competition" depends on the number of dealerships in a market and which dealerships are in a market (e.g., GM vs non-GM). Given this interpretation, if a market's sales potential sales is reasonably fixed, then it is intuitive that entry (i.e., more competition) could reduce each firm's sales (the fixed market potential is allocated among more firms). However, entry could increase a retailer's sales either because price competition is sufficiently severe to increase total sales (i.e., total potential demand increases) or via a retail agglomeration effect - consumers may be more likely to search a retailer located near other retailers rather than an isolated retailer because the

\footnotetext{
${ }^{1}$ This is a "statistical" notion of economies of scale because the coefficient of variation is decreasing in sales (when $\beta<1$ ). Inventory theory also suggests the possibility of economies of scale due to batching, such as in the EOQ or $(R, Q)$ models. Inspection of our time series does not reveal a strong "saw-tooth" pattern that one would expect in the presence of batching.

${ }^{2}$ Gaur et al. (2005b) measures $\beta$ using public data from the U.S. retail sector, obtaining estimates from 0.55 to 0.73 .
} 
consumer wishes to economize on search costs. ${ }^{3}$ We are not directly concerned with the specific mechanism by which competition influences sales because we conjecture that these mechanisms influence inventory only through their effect on sales.

A retailer's service level choice depends on the retailer's estimates of the cost of stocking too much inventory (the overage costs) relative to the cost of stocking too little inventory (the underage cost). The overage cost is composed of the opportunity cost of capital, storage costs and depreciation. The underage cost depends on the behavior of consumers when they do not find their preferred product (which may depend, in part, on consumer characteristics like brand preferences, income, etc.) In such a situation a consumer could purchase some other product at the retailer (substitute), defer purchase of the most preferred product to a later time (backorder) or leave the retailer without making a purchase (the no-purchase option). The retailer's optimal service level depends on the ratio of these costs: as the underage cost increases relative to the overage cost, the retailer's optimal service level increases.

With this understanding of how a retailer chooses a service level, we conjecture that there are three mechanisms by which competition influences the service level component of (4): a margin mechanism, a demand-retention mechanism and a demand-attraction mechanism. The margin mechanism is simply that additional competitors increases the intensity of price competition, which lower margins, thereby decreasing the underage cost, i.e., a smaller margin reduces the consequence of losing a customer due to a stock out, thereby lowering the incentive to hold inventory. The demand-retention mechanism influences underage costs via consumer behavior once the consumer has chosen to shop at a retailer. As more competitors enter a market, consumers are more likely to choose the "no-purchase" option relative to the "substitute" or "backorder" option, thereby leading to higher underage costs. Therefore, the margin and demand-retention mechanisms counteract each other. The demand-attraction mechanism states that a higher service level may attract more demand to a retailer (i.e., influence their choice of where to shop), because, all else being equal, a consumer prefers to shop at a retailer with a higher service level (See Dana and Petruzzi (2001) and Gerchak and Wang (1994) for single-firm models in which service level is used to attract demand.) According to the demand-attraction mechanism, more competition causes firms to increase their service level to build their market share.

There is theoretical support for these three mechanisms that link competition to service level.

\footnotetext{
${ }^{3}$ See Dudey (1990), Eaton and Lipsey (1982), Stahl (1982) and Wolinsky (1983) for models of consumer search in which firm location decisions are endogenous.
} 
Deneckere and Peck (1995) consider a model in which both the margin and demand-attraction mechanisms are active but find that they offset each other - service levels are independent of the number of competitors. However, Dana (2001) modifies their model and indeed finds that entry can reduce service levels. The analogous conclusion can be inferred from Bernstein and Federgruen (2005). ${ }^{4}$ Other models find that competition induces firms to reduce their service level even if a $100 \%$ service level is costless, because lower service levels dampen price competition (see Balachander and Farquhar (1994) and Daugherty and Reinganum (1991)). Consistent with these models, Gaur et al. (2005a) find that retailers with lower margins carry lower inventory and Amihud and Mendelson (1989) provide evidence of a direct link between market power and inventory levels. ${ }^{5}$ However, Cachon (2003) develops a specialized version of the Deneckere and Peck (1995) model in which service levels are increasing in the number of competitors: firms use service level more aggressively to attract demand when they face more competition.

The demand-retention effect is absent in the Deneckere and Peck (1995) model (and its derivatives) but it is included in Cachon et al. (2006) and Watson (2006). They show that firms increase their service level as they face more competition because a higher service level reduces the chance a consumer continues searching/shopping.

There are a number of papers that study inventory competition (e.g., Lippman and McCardle (1997), Mahajan and van Ryzin (2001), Netessine and Rudi (2003)) but those models neither have a demand-attractive effect (the demand allocated to a retailer does not depend on his inventory) nor a margin-effect (price is assumed to be fixed), nor a demand-retention effect (firms do not influence whether consumers choose to purchase or continue shopping). As a result, competition and service level are independent of each other in those models.

To summarize, theoretical models of inventory competition provide contradictory guidance with respect to the relationship between service levels and competition. Additional competition reduces service levels if the impact of price competition on margins is severe, whereas additional competition increases service levels if higher service levels either attract additional demand or help to retain demand.

We now further elaborate on (4). For each retailer $r$ and product category $b$, we have shown that inventory, $I_{r b}$, is determined by a combination of sales, $S_{r b}$, and the service level, $z_{r b}$. (We

\footnotetext{
${ }^{4}$ If prices decrease, Bernstein and Federgruen (2005) find that service levels decrease, but they do not explicitly study the impact of competition, and their model is ill suited to do so.

${ }^{5}$ Gaur et al. (2005a) do not directly link retail competition to inventory level - they only observe a correlation between margins and inventory turnover.
} 
distinguish products by category because it is plausible that inventory levels across categories at the same retailer have different motivations to hold inventory.) We use the index $i$ to denote each $(r, b)$ observation and $m(i)$ to denote the relevant market for observation $i$. Competition can influence sales and service level, but there are other factors describing a market that could influence service level (e.g., consumer characteristics). Let $W_{m(i)}$ be a (column) vector of observable covariates capturing the characteristics of the local market that affect the service level of observation $i$. (Throughout the paper, we use column vectors for covariates and row vectors for parameters.) However, different observations from the same local market can have different service levels; that is, there may be factors specific to a retailer or product category that affect its service level. The vector $V_{i}$ captures observable factors of this kind. For example, $V_{i}$ may include factors describing the supply process of a retailer or a vector of brand dummies.

We assume the following reduced form for the service level component:

$$
\log K\left(z_{i}\right)=\beta_{v} V_{i}+\gamma W_{m(i)}+\xi_{m(i)}+\nu_{i}
$$

The error term $\xi_{m(i)}$ captures unobserved factors relevant to the local market $m(i)$ (i.e., to all retailer/category pairs within market $m(i)) ; \nu_{i}$ denotes other unobserved factors specific to observation $i$. The term $\gamma W_{m(i)}+\xi_{m(i)}$ is the effect of local market conditions on service level. A subset of the covariates in $W$, denoted by $C_{m(i)}$, capture the intensity of competition in market $m(i)$. As described later, in our data analysis $C_{m(i)}$ includes the number of dealers in a market, the square of the number of dealers and in some specifications, the number of GM dealers. The term $\gamma_{c} C_{m(i)}$ measures the overall impact of competition within the market on service level, including price competition and inventory competition effects (e.g. demand attraction/retention effects); therefore, its sign is ambiguous. We refer to $\gamma_{c} C_{m(i)}$ as the service level effect. Other covariates in $W$ include an intercept and demographic characteristics of the markets that capture differences in consumer characteristics which influence a retailer's optimal service level.

Replacing (5) in (4) gives the following model, which can be estimated with data from a cross section of retailers:

$$
y_{i}=\beta X_{i}+\gamma W_{m(i)}+\xi_{m(i)}+\nu_{i}
$$

where $y_{i}=\log I_{i}, X_{i}=\left(\log S_{i}, V_{i}\right)$ and $\beta=\left(\beta_{s}, \beta_{v}\right)$. The parameter vector to be estimated is $\theta=(\beta, \gamma)$. We are interested in the magnitude of the coefficient of sales $\beta_{s}\left(\beta_{s}=1\right.$ means there are no economies of scale with respect to sales) and the sign and magnitude of the service level 
effect $\left(\gamma_{c}<0\right.$ suggests that the price effect of competition dominates whereas $\gamma_{c}>0$ suggests that the demand attraction/retention effects dominate).

\section{Estimation method}

There are several challenges associated with the identification of $\theta$. It is important to define each retailer's market appropriately, otherwise $W$ may be a poor measure for local market characteristics. This concern can be alleviated by identifying geographically isolated markets (a similar approach was used by Bresnahan and Reiss (1991)). To estimate $\gamma_{c}$ precisely, it is important that the selected markets have sufficient variation in the degree of competition.

The endogeneity of some of the variables in $X$ and $W$ is of particular concern with respect to the identification of $\theta$. Sales is affected by product popularity, which may also affect customer purchase behavior (e.g., the propensity to backorder) and therefore the service level chosen by retailers. While the demographic variables in $W$ capture part of the heterogeneity in consumer characteristics across markets, some customer characteristics are unobservable and will enter in $\xi$. If a market has consumers with a high affinity to purchase the retailers' products and these consumer tastes are not fully captured by the covariates in $W$, then we would expect $\xi$ to be correlated with sales. Hence, estimating (6) with Ordinary Least Squares (OLS) leads to biased estimates of $\theta$.

Measures of competition are subject to a similar endogeneity bias. Retailers choose which markets to enter and they may do so based on market characteristics that they observe but are unobserved by the econometrician. Inventory costs affect dealership profits, therefore entry decisions are affected by local market characteristics that influence inventory, including $\xi$. If such is the case, $C$ and $\xi$ may be correlated. Intuition suggests this correlation is negative: high service levels (high $\xi)$ raise total inventory costs, leading to lower profits and fewer entrants (low $C$ ). This suggests a downward bias in estimating $\gamma_{c} C$ through OLS.

We propose a two step method to estimate $\theta$. In the first step, use a within-market estimator of $\beta$ which accounts for the endogeneity of sales. In the second step, replace $\beta$ in (6) with this estimate and estimate the modified (6) using Instrumental Variables to account for the endogeneity of competition (i.e., the number of retailers). We describe in detail this two step method in what follows.

In the first step, estimate $\beta$ by comparing retailers located in the same local market. Define the set $M_{m}=\{i: m(i)=m\}$ which contains all observations from market $m$. Also, let $\bar{X}_{m}=$ 
$\frac{1}{\left|M_{m}\right|} \sum_{i \in M_{m}} X_{i}$ and $\bar{y}_{m}=\frac{1}{\left|M_{m}\right|} \sum_{i \in M_{m}} y_{i}$. Transform the dependent variable $\dot{y}_{i}=y_{i}-\bar{y}_{m(i)}$ and the covariates $\dot{X}_{i}=X_{i}-\bar{X}_{m(i)}$ to re-write (6) as

$$
\dot{y}_{i}=\beta \dot{X}_{i}+\nu_{i}
$$

Assuming $E\left(\dot{X}_{i} \nu_{i}\right)=0$, estimating (7) using OLS gives a consistent estimate of $\beta$. The main advantage of this model with respect to (6) is that it allows consistent estimation of $\beta$ even when some of the covariates in $X$ (e.g. sales) are correlated with $\xi$. Its main disadvantage is that the effect of local market conditions, $\gamma W_{m(i)}+\xi_{m(i)}$, are not estimated.

The second step estimates $\gamma$ using the estimated coefficient $\hat{\beta}$. Replace $\beta$ in (6) with $\hat{\beta}$ and rearrange to produce

$$
y_{i}-\hat{\beta} X_{i}=\gamma W_{m(i)}+\varepsilon_{i}
$$

where $\varepsilon_{i}=\xi_{m(i)}+\nu_{i}$. We suggest estimating (8) using Instrumental Variables (IV) to instrument for the endogeneity of competition. We seek factors excluded from $W_{m(i)}$ that are correlated with competition but uncorrelated with unobservable consumer characteristics that enter in $\xi_{m(i)}$. In our subsequent data analysis, we use measures of market population as our main instruments on the assumption that population is correlated with entry (more firms enter as a market's population increases) and population is uncorrelated with unobserved consumer characteristics that influence service level conditional on the observed controls in $W_{m(i)} \cdot{ }^{6}$ The exogenous instruments, denoted by $Z$, include several measures of population and the demographics in $W$. $Z$ does not include covariates in $X$ or the measures of competition, $C$. Assuming $E\left(Z_{i} \varepsilon_{i}\right)=0$, estimating (8) using Two Stage Least Squares (2SLS) gives a consistent estimator of $\gamma$.

Our two-step method estimates $\theta$ consistently based on two moment conditions: $E\left(\dot{X}_{i} \nu_{i}\right)=0$ and $E\left(Z_{i} \varepsilon_{i}\right)=0$. Instead of using a two-step method, it is possible to estimate these moment conditions jointly using Generalized Method of Moments (GMM). (See the appendix for details.) There are two main advantages of the GMM approach. First, it is more efficient (the estimation is more precise). (See Wooldridge (2002), Section 8.3 for details on the statistical properties of GMM.) Second, the standard errors provided by the 2SLS in the second step of the two-step method are not correct because the regression includes variables which are estimated $\left(\hat{\beta} X_{i}\right)$. The standard errors from the joint estimation using GMM are correct (and therefore can be used to validate hypothesis testing). The main drawback from using GMM is that $\beta$ is biased when the

\footnotetext{
${ }^{6}$ The assumption that larger markets lead to more entry can be verified empirically when markets are well defined. See Bresnahan and Reiss (1990) for empirical evidence of the effect of population on entry in auto dealership markets.
} 
second moment condition $E\left(Z_{i} \varepsilon_{i}\right)=0$ is misspecified (i.e., when some of the covariates in $Z$ are not exogenous). In addition, common statistics used to evaluate the goodness of fit in regressions (e.g. $R^{2}$ ) are not available for GMM.

\section{Data and Model Specification}

This section begins with a brief description of the U.S. auto industry and then details the data in our study. During the period of our study, six companies accounted for about $90 \%$ of sales in the U.S. auto market: Chrysler, Ford, GM, Honda, Nissan and Toyota. ${ }^{7}$ We refer to Chrysler, Ford and GM as domestic manufacturers. Each company offers vehicles under several brands. For example, GM brands include Chevrolet, GMC, Pontiac, Buick, Saturn, Cadillac and Hummer. Each brand produces several models. Examples include the Chevrolet Malibu, the Toyota Camry and the Ford Explorer. Models can be classified into vehicle classes, including cars, sports cars, Sport Utility Vehicles (SUV) and pickups, among others.

In the U.S., auto distribution is regulated by franchise laws, which require that all new vehicles must be sold through a network of dedicated franchised dealers. (See Smith (1982) for details on dealership franchise laws.) In 2006 there were approximately 22,000 dealerships in the U.S. The number of dealerships has been declining in the U.S. since it peak in 1930 when there were about 50,000 dealerships (Marx (1985)). Furthermore, dealerships are not uniformly distributed across the U.S.. In states with large population growth from 1950 - 2004, such as Arizona, there is approximately the same number of GM and Japanese brand dealerships, whereas in slow growth states, such as Iowa, GM dealerships are much more numerous in a relative sense.

\subsection{Primary data}

Based on (6), we seek to define isolated markets so that we can accurately proxy for the level of competition within the market. We begin with Urban Areas (UA) defined in the 2000 Census and with population below $150,000{ }^{8}$. We designate an UA as isolated if it meets the criteria summarized in Table 2. These criteria impose minimum distance requirements to markets of equal or larger size with the rationale that consumers who do not find their desired product inside their

\footnotetext{
${ }^{7}$ Chrysler was owned by Daimler-Chrysler but we refer to this manufacturer as "Chrysler". In May 2007 (after our data collection period) it changed ownership to a private equity firm, Cerberus Capital Management.

${ }^{8}$ These include: (i) urbanized areas "consisting of territory with a general population density of at least 1,000 people per square mile of land area that together have a minimum residential population of at least 50,000 people"; and (ii) urban clusters of "densely settled territory with at least 2,500 people but fewer than 50,000". (quoted from Census glossary, www.census.gov)
} 
market will try to find that product in the closest more populous market. Dranove et al. (1992) and Bresnahan and Reiss (1991) use similar criteria to define isolated markets. From this set of markets, we selected for our study the 235 markets that have at least one GM dealership. (As we describe later, our data are from GM dealerships.) We obtained demographic data and geo-coded information (latitude and longitude) for these markets from the 2000 decennial census. 37\%, 5\%, $26 \%$ and $31 \%$ of the markets are located in the Mid-West, North-East, South and West census regions, respectively. Figure 1 provides a map indicating their locations.

Data on new vehicle dealerships located in each market were obtained from edmunds.com. ${ }^{9}$ The definition of an automobile dealership is somewhat ambiguous. For example, a dealer may operate brands of different manufacturers, but generally the vehicles of different manufacturers are shown in separated showrooms. Sometimes the showrooms are listed with different addresses or telephone numbers. We defined a dealership as a geographic location- a US Postal Service standard addressthat carries vehicles of one manufacturer. If a location happens to indicate brands from two or more manufacturers, we count them as multiple dealerships (one for each manufacturer). With this definition, it is possible to have markets with multiple dealerships which are jointly owned. We classify these as distinct dealers because the inventory in these showrooms are probably managed separately and this leads to a conservative measure of competition if they are managed jointly. For robustness, in Section 5 we report results with alternative criteria to define dealerships.

Table 3 describes the selected markets, grouped according to the total number of Ford, Chrysler, GM, Honda, Toyota and Nissan dealerships. The second column shows the number of markets with the observed number of dealers. For example, there are 10 markets with one GM dealership. In more than $90 \%$ of the markets there are 10 or fewer dealerships. The number of dealerships increases with market size, measured by population (third column). The last three columns show the percent of markets with at least one dealership of a non-GM domestic manufacturer (Ford or Chrysler), Japanese manufacturer (Toyota, Honda or Nissan) and a second GM dealership, respectively. The first two competitors faced by a GM dealer are usually non-GM domestic dealerships. Japanese dealerships usually exist in markets with three or more dealerships. In almost all markets with two or more GM dealers, the GM dealers carry different brands ${ }^{10}$. The table shows that the selected markets have sufficiently rich variation in competition, both in the number and type of dealerships.

\footnotetext{
${ }^{9}$ We matched dealers to UA based on 5 digit zipcodes. Matching tables were obtained from the Missouri Census Data Center (http://mcdc2.missouri.edu).

${ }^{10}$ Only 4 markets have GM dealerships with overlapping GM brands.
} 
We obtained inventory and sales data from a website offered by GM (http://www.gmbuypower.com) that enables customers to search new vehicle inventory at local dealerships. We developed a webcrawler that each day monitored inventory in all the GM dealerships located in our selected markets (and only GM dealerships ${ }^{11}$ ) from August 15, 2006 to February 15, 2007 (six months of data). The web-crawler recorded the number and type of vehicles available at each dealership (e.g., the number of GMC Yukon 2007 4WD available at each dealer) along with specific information on each vehicle, such as color, options, list price and, most importantly, the vehicle identification number (VIN). VINs uniquely identify all new vehicles in the U.S. Therefore, by keeping track of the VINs available at each dealership, we are able to identify replenishments (a vehicle is added to a dealer's inventory) and sales (a vehicle is removed from a dealer's inventory). We also can identify dealer transfers (a vehicle removed from one dealer's inventory and added to another dealer's inventory) among the dealers in our sample. However, to identify all dealer transfers would require monitoring all dealers in the U.S., which was not feasible. Instead, we monitored all dealerships in seven states, which we believe allows us to identify most of the transfers occurring in our sample markets in those states. The sensitivity analysis on section 5 shows that the results are similar when restricting the sample to dealerships in these 7 states. $^{12}$

To validate our data, we visited three dealerships in the Philadelphia area. Most of the vehicles found at these dealers on June 2, 2006 were posted on the website during that day. The dealerships visited declined to provide data on the specific vehicles sold. ${ }^{13}$

We obtained the following demographic data for each market: percent of population above 60 years old $(E L D E R)$, that is African-American $(B L A C K)$, with a college degree (COLLEGE), active in the army $(A R M Y)$, involved in a farming occupation (FARMING) and that commutes to work with public transportation (PUBTRANS). We also obtained median household income for each $\mathrm{UA}(I N C O M E)$.

We included BLACK, INCOME, COLLEGE, ELDER, and FARMING in $W$ because these variables have substantial partial correlation with the number of dealerships in a market. In addition, we included PUBTRANS and ARMY (to capture potential differences in consumer characteris-

\footnotetext{
${ }^{11}$ Developing web-crawlers for each manufacturer would require substantial additional effort. We monitored our web-crawler frequently in case changes were made to the website. In fact, during our study period GM did change its website. Substantial effort was required to repair the crawler.

${ }^{12}$ The selected states are Colorado, Nebraska, Florida, Wisconsin, Maine, California and Texas. These states are geographically relatively isolated (they border Mexico or Canada, they have a substantial coastline and/or their border areas are sparsely populated) and exhibit variation in population growth.

${ }^{13}$ We selected this dealerships by convenience. None of the selected markets are in the Philadelphia area. The dealership lots include many vehicles (sometimes more than 100) and the authors could not verify all of them.
} 
tics and their affinity for domestic brands) and indicators of the census region where the UA is located. ${ }^{14}$

\subsection{Model specification}

To estimate model (6), we defined the dependent variable as the average vehicle inventory of each brand at a GM dealership (INV), i.e., the dependent variable is inventory at a dealer-brand pair. (HUMMER is excluded from our analysis because it is present in only one of our study markets.) We evaluated total sales (SALES) of each brand at each dealership during the study period to measure expected sales. (Sales includes vehicles transferred to other dealerships.)

Several different measures of competition are included in $C$. The simplest measure is the number of dealerships in the market $(N D)$. We restricted the dealership counts to the following manufacturers: GM, Chrysler, Ford, Toyota, Honda and Nissan. We included the square of this variable $(N D S Q)$ to capture non-linearities in the effect of competition. We also estimated the effect of the number of rivals using a flexible non-parametric specification, with indicator variables of the form $\delta_{x}=1\{N D=x\}$, with $x \in\left\{1 . . N_{\max }\right\}$. We restricted our sample to markets with 8 or fewer dealerships to measure this effect more precisely $\left(N_{\max }=8\right) .{ }^{15}$ In some specifications, we also include the number of GM dealerships in the market $(N G M)$ to test whether the effect of competition varies across different types of dealerships.

To measure potential competition from outside the market, we included a covariate in $W$ that measures the driving time, in hours, to the closest GM dealership outside the UA (OUTSIDE) We used driving time to capture the effect of nearby highways on transportation $\operatorname{costs}^{16}$. We also estimated models with "bird-fly" distance and to GM dealerships carrying the same brand. Our results were similar with these alternative measures.

GM dealerships can own multiple GM brands. If customers substitute between different GM brands, a stock-out in one brands is less likely to become a lost sale for a multi-brand dealership, because customers may buy a vehicle from another brand on the lot. If substitution within GM

\footnotetext{
${ }^{14}$ Previous work estimating demand for automobiles have used similar measures to capture age, income, occupation and race (e.g. Berry et al. (2004), Agarwal and Ratchford (1980)). Marketing research firms focused in the auto industry collect similar data (e.g. R.L. Polk, http://usa.polk.com). We also estimated specifications which included additional demographics, including voter turnout, the percent of Republican votes, the percent Latino in the population, and the average number of vehicles per household, among others. The results in these specifications were similar to those reported in Section 4. Some of these additional variables were not available for all markets, so we decided to exclude them from our main results. Some of the demographics included in our main results are not statistically significant, but excluding them from the analysis does not change our main results.

${ }^{15}$ We also expanded our sample including markets with 9 and 10 dealerships and our results were similar.

${ }^{16}$ The data was retrieved from http://www.randmcnally.com.
} 
brands is substantial, we expect the number of GM brands carried by a dealership (NBRAND) to have a negative effect on the service level. This dealer specific measure is included as a covariate in $X$. Brand dummies were also included in $X$ to control for differences in customer loyalty and preferences that can influence service level.

The service level may also be affected by a dealership's supply process. For example, transfers between dealerships enable dealerships to share inventory, which helps to reduce inventory. ${ }^{17}$ Therefore, we include a measure of transfers as a control variable in $X$. Let $T_{r b}$ be the total amount of transfers received by dealership $r$ of brand $b$ and let $Q_{r b}$ be the total incoming orders (without transfers from other dealerships) received. For observation $i=(r, b)$, we measure the percent of transfers received as: $T R A N S F_{i}=T_{i} /\left(T_{i}+Q_{i}\right)$. We expect TRANSF to have a negative effect on average inventory levels. Recall, we are unlikely to observe all of the transfers for all dealerships. We include a dummy, ALLSTATE, to indicate whether the dealership is located in one of the states where we monitored all dealerships. ${ }^{18}$

We found some outliers in our sample. Two dealerships located in Alaska were extremely isolated (the driving time to the closest GM dealership, OUTSIDE, was more than 6 hours). These two dealerships (3 observations in total) were removed from the sample. ${ }^{19}$ The final sample contains 654 observations in 178 markets. Table 4 shows summary statistics and the correlation matrix of the main variables in the econometric model.

\subsection{Instrumental variables}

We use total population in the UA (UAPOP), fringe population (FRINGEPOP) and population density $(D E N S)$ to instrument for competition. The fringe population of a UA is defined as the population of all zipcodes outside the UA within a 100 miles radius for which the UA is the closest UA with dealerships ${ }^{20}$. We also used measures of past population as instruments: county

\footnotetext{
${ }^{17}$ Anupindi and Bassok (1992) show that centralization of inventory stocks of multiple retailers usually decreases total inventory relative to the decentralized case where each retailer chooses their inventory level independently. Rudi et al. (2001) analyze a model of two newsvendors with transshipments of left-over inventory. It can be shown that their model implies a negative association between the average number of transfers received by a retailer and its service level. Narus and Anderson (1996) report inventory reductions from inventory sharing initiatives in several industries operating with decentralized distribution networks.

${ }^{18}$ If the coefficient on TRANSF is negative, we expect ALLSTATE to be positive because for the observations with $A L L S T A T E=0$ a fraction of the transfers are unobserved. In all the specifications analyzed, the coefficient on ALLSTATE was positive and significant. The average percent of transfers for dealerships with $A L L S T A T E=0$ and ALLSTATE $=1$ is $4.5 \%$ and $10 \%$, respectively. ALLSTATE is market specific and is therefore included in $W$.

${ }^{19}$ Including them in the sample changes the coefficient of OUTSIDE, but the other estimates are similar.

${ }^{20}$ A similar measure was used by Dranove et al. (1992). We calculated distances using latitude and longitude. The census proxy of zipcodes (Zip Code Tabulation Area, ZCTA) were used.
} 
population and density in 1950 and 1970 (POP50, POP70, DENS50, DENS70). Franchising laws impose costs on the manufacturer to close existing dealerships. Markets with current low population which had higher population in the past are likely to have more dealerships than those which never had a large population. Due to this "stickiness" in dealership exit, past population has positive partial correlation (conditional on current population) with the number of dealerships. All population measures were included with natural log transformation because it provided better fit in the first stage estimates of the 2SLS regressions. As mentioned earlier, population growth rate is associated with higher entry of dealerships, so we defined two additional instruments that depend on county population growth between 1950 and 2000 (denoted $g$ ): $P G W T H=\max (0, g)$ and $N G W T H=\max (0,-g) .{ }^{21} \mathrm{UA}$ population was obtained from the 2000 decennial census. Historical county population was obtained from the Inter-University Consortium for Political and Social Sciences (ICPSR).

\section{Results}

In this section, we discuss the results reported in Table 5 which displays the estimation results. Column (1) shows the estimates of the first step of our two step method. Columns (2)-(4) show different specifications for the second step of the method. Column (5) shows the joint GMM estimates. The coefficients for the demographics and the dummies for brand, region and ALLSTATE are omitted for ease of visualization.

Column (1) shows that the point estimates of the coefficient of $\log S A L E S\left(\beta_{s}\right)$ is measured with precision and is below one with statistical significance. The magnitude of the $\beta$ coefficient suggest substantial economies of scale: a $10 \%$ increase in sales translates into only a $6.3 \%$ increase in inventory. The use of transfers from other dealerships, measured by TRANSF, has a large economic (and statistically significant) effect in reducing inventory levels. Increasing TRANSF by 0.1 (a 10\% increase in the fraction of supply received from transfers) reduces inventory by approximately $8 \%$. The coefficient on NBRAND is small and not significant. The coefficient of determination $\left(R^{2}\right)$ is high, suggesting that a substantial fraction of the within-market variation on inventory can be explained by the covariates included in $X$.

Column (2) shows the estimates of the service level effect of competition $\left(\gamma_{c}\right)$ using OLS. The specification includes a linear and a quadratic term of the number of dealerships in the market

\footnotetext{
${ }^{21}$ Bresnahan and Reiss (1990) uses similar functions of population growth to capture entry in auto dealership markets.
} 
( $N D$ and $N D S Q$ ). The estimates suggest that the effect of competition is positive and marginally decreasing. Figure 2 illustrates the estimated impact of the number of dealerships on inventory, measured by the percent change relative to a monopolist. The figure shows the effect of competition through service level only (sales is kept constant). Upper and lower bounds of the $95 \%$ confidence interval are illustrated with + and - symbols, respectively (standard errors are calculated using the delta method, see Hayashi (2000)). The squares in the figure plot the estimates from a flexible specification using indicator variables for each level of competition (the $\delta_{x}$ variables). Interestingly, the more parsimonious quadratic polynomial model provides a good approximation of the flexible model. In all the specifications analyzed, the coefficient of OUTSIDE is negative, suggesting that inventory tends to increase with the proximity of GM dealerships outside the market. This effect is consistent with the positive coefficient on $N D$, but the economic significance of OUTSIDE is smaller: reducing OUTSIDE one standard deviation at the mean increases inventory by $3.5 \%$, while increasing $N D$ by one standard deviation at the mean increases inventory by $12.5 \%$.

Column (3) estimates equation (8) using IVs to instrument for the endogenous variables ND and NDSQ. IVs include UAPOP, FRINGEPOP, PGWTH, NGWTH, DENS and past population and density variables. Even though the estimates are less precise than in (2), they suggest a similar pattern for the service level effect. $N D$ and $N D S Q$ are jointly significant (the p-value of the F-test is less than 0.001 ) and both $N D$ and $N D S Q$ coefficients are significantly different from zero at the $10 \%$ confidence level. In fact, the service level effect suggested by the IV estimates is slightly larger than the OLS estimate: a one standard deviation increase of $N D$ at the mean increases inventory by $16.5 \%$. However, we cannot reject that the coefficients of $N D$ and $N D S Q$ of specifications (2) and (3) are different with statistical significance (p-value $>8 \%$ ). The $R^{2}$ of the first stage regression of the 2SLS (with $N D$ as the dependent variable) is $0.68 .^{22}$

Columns (4) includes the number of GM dealerships (NGM) as an additional measure of competition. The estimates suggest that the effect of entry of a rival GM dealership has a larger positive effect compared to the effect of an average dealer.

Column (5) reports the joint GMM estimates. The instruments used in these estimations include exogenous variables in $W$ and the IVs use in specification (3). Hence, the estimates of column (5) are comparable to those of (3). The point estimates of the estimated coefficients obtained through GMM (column (5)) and the two step method (column (3)) are similar in magnitude but the GMM

\footnotetext{
${ }^{22}$ The first stage estimates can obtained from the authors upon request.
} 
estimation is more precise. The $N D$ and $N D S Q$ coefficients are significant at the $1 \%$ confidence level, respectively. Because the asymptotic standard errors of the GMM estimates are correct, this validates the statistical significance of our results. ${ }^{23}$

Both the OLS and IV estimates suggest a positive and marginally decreasing effect of competition on service level. While the point estimates of OLS and IV are different, the elasticities at the mean are similar in magnitude. The statistical evidence cannot reject that the OLS estimates are unbiased. Given the higher precision of the OLS estimates, we focus the discussion on the results of specifications (2) and (4).

Our result contrast somewhat with the findings in Gaur et al. (2005a) and Amihud and Mendelson (1989). Gaur et al. (2005a) finds that as a retailer lowers its margin, it tends to carry less inventory. (Amihud and Mendelson (1989) has a similar finding but they study manufacturing firms.) If low margins are taken as a proxy for more intense competition, then they find that inventory decreases with competition. They do not study auto retailing, so it is possible that in other retail markets the margin effect of entry dominates the demand attraction/retention effects. Alternatively, margins in their data may proxy for something other than competition. (They control for deviations from sales forecast but not for sales volume, so it is possible that in their analysis gross margin also proxies for sales volume.) Further research is needed to reconcile these issues and findings.

\section{Sensitivity analysis and further empirical evidence}

In this section, we discuss the representativeness of our sample, report on a sensitivity analysis and provide additional empirical evidence to test the robustness of our results.

Our results provide direct evidence of the reaction of a sample of GM dealerships to competition within the U.S. Without additional data, it is not possible to convincingly claim whether or not dealers from other automobile manufacturers react in a similar manner. Furthermore, while it is possible that retailers in other industries increase their inventory holdings when faced with additional competition, additional data collection and analysis is needed to evaluate this conjecture.

Given that we analyzed isolated markets, there is a question as to whether our results apply to all GM dealerships. To explore this issue, recall that we collected inventory and sales data from all dealer-brand pairs in seven states, the ALLSTATE dealerships. Using that data set, we regress

\footnotetext{
${ }^{23}$ We also estimated specifications (2) and (4) through GMM and the estimates were also similar.
} 
days-of-supply at dealer-brand pairs on a dummy variable indicator of whether the dealer-brand is in our isolated market set, INIM, and controls for state and brand. In a second regression we include the $\log$ of the population of the dealer-brand's market, $\log P O P$. As reported in Table 6 , on average, dealers in our selected markets carry about $8 \%$ less inventory relative to dealers located in the same state and same brand, but if we control for population, the coefficient on INIM decreases and becomes statistically insignificant, which suggests that they are not different than GM dealers outside our sample in terms of their inventory holdings.

As an additional check, we compared our estimates of days-of-supply in our ALLSTATE states to days-of-supply data from Wards Auto for the same period and report the results in Table 7 . We find that our days-of-supply match Ward's closely for both Cadillac and Saturn. For the other GM brands our days-of-supply is higher than Ward's but they include fleet sales (e.g., government agencies, car rental companies) in their calculation of sales whereas we do not (we presume that fleet sales are not recorded in dealers' inventories and instead flow directly to the customer). We evaluated the amount of fleet sales that would be required for our data to match Ward's. Fleet sales of about $20-25 \%$ is plausible for those brands. The results from Table 7 provide some evidence that our sample reasonably matches the publicly reported data by Ward's. ${ }^{24}$

In our main results, we control for systematic differences in inventory levels across GM brands (through the brand dummies), but the coefficients on competition are restricted to be equal across brands. Hence, our estimates show the average effect of competition on inventory, and it would be of interest to determine whether this effect varies across brands. Restricting the sample to specific brands reduces the sample size significantly, reducing the precision of the estimates. But we were able to repeat our analysis in a sub-sample that contained only Chevrolet dealerships, which were present in 170 of the 178 markets. The results over this sub-sample were qualitatively similar to those reported in Table 5: the estimates also suggest a positive and marginally decreasing effect of competition on service level. Increasing the number of dealerships by one (at the mean) increases inventory by approximately $9 \%$ (in our main results, this elasticity is $8 \%$ ). ${ }^{25}$

We conducted several regression diagnostics. We found no major influential points in the sample.

\footnotetext{
${ }^{24}$ Ward's includes all states, whereas we include only seven states, so that could explain some of the differences as well. Furthermore, we report days-of-supply as the average of ratios across dealers, whereas Wards' reports the ratio of averages. Our analysis (details available from the authors) indicates that this could explain some of the differences but fleet sales seems more likely to be the main explanatory factor.

${ }^{25}$ Recall, the estimation of $\beta$ uses variation across dealerships in the same market. Therefore, we continue to use dealerships from all brands to do the first step estimation. In the second step, the sub-sample of Chevrolet dealership is used to estimate $\gamma$.
} 
The variance inflation factors are all below four, suggesting that multi-collinearity is not a major issue. A Breusch-Pagan test suggest heteroscedasticity of the error term $\nu_{i}$, so we report robust standard errors for the first step regression (for the second step regression the $p$-value of the test is 0.28 , suggesting homoscedasticity of the error term $\varepsilon_{i}$ ).

Model (6) suggests a linear relationship between the logarithms of inventory and sales, and requires a constant $\beta_{s}$ across markets with different market structures. A scatter plot of $\log I N V$ versus $\log S A L E S$ reveals a strong linear relationship between the two variables in three types of markets: markets with a single GM dealership, markets with GM and non-GM domestic dealers, and markets with all kinds of dealerships (GM, non-GM domestic and Japanese). A regression of $\log I N V$ on $\log S A L E S$ allowing for different slopes and intercepts across the three groups yields $R^{2}=0.95$ and fails to reject the hypothesis of equal slopes across the three series $(p=0.36) .{ }^{26}$ This analysis suggests there are no interaction effects between $\log S A L E S$ and competition, i.e., the effect of competition on service level is separable from the effect of sales.

Regressions over the sub-sample of dealerships with $A L L S T A T E=1$ yield estimates that are similar in magnitude, sign and statistical significance to those reported in Table 5.

Model (6) can be subject to non-classical measurement error bias if average inventory and sales are estimated from a short interval of time. To explain, suppose only one week of daily observations are available to evaluate $I N V$ (average inventory level) and $S A L E S$ (a dealer's expected sales). If sales during that week were below average, then $I N V$ overestimates average inventory and $S A L E S$ underestimates expected sales. The measurement errors of $I N V$ and $S A L E S$ are then negatively correlated, and so the coefficient on sales, $\beta_{s}$, is likely to be downward biased. We replicated our analysis using three months of data and the results were basically identical to our main results (data from a six month period), which suggests that this potential measurement error bias is small in our analysis.

We estimated the econometric model using alternative dealership definitions. We defined a measure based on ownership: if two or more dealerships located in the same market are jointly owned, they are counted as a single dealership. Because we do not have data on ownership, we used the following criteria to assess whether dealerships are jointly owned: (1) they are listed with the same US Postal Service address; or (2) they have the same telephone; or (3) they have similar names. ${ }^{27}$ With this alternative definition, the mean number of dealerships per market is 3.4 (the

\footnotetext{
${ }^{26}$ In pairwise tests of the coefficients the smallest $p$ value was 0.18 .

${ }^{27}$ To match names, all words in the dealer names have to match. To be conservative in the matching, we do not
} 
standard deviation is 1.7). We estimated the model replacing $N D$ with this new measure. The coefficients of $N D$ and $N D S Q$ are .21 and -0.018, respectively, both statistically significant (pvalue $<.01)$. These results also suggest a positive and marginally decreasing effect of competition on service level. Increasing competition by one standard deviation at the mean increases inventory in approximately 10\%, similar to what we obtained with our previous dealership definition.

We also estimated the model using the number of brands offered in the market as the measure of competition. For example, if a Chrysler dealership sells vehicles from Dodge and Jeep (two brands of this manufacturer), we counted them as two competitors. As before, the effect of this competition measure is positive and statistically significant. Increasing $N D$ by one standard deviation at the mean raises inventory approximately $5 \% .^{28}$

\section{Further evidence of the effect of competition on service level}

To estimate equation (6), we use market population as an IV to identify a causal effect of competition on service level (section 4). The main concern with OLS is that the positive correlation between competition and service level could be driven by unobserved factors that affect both variables rather than a causal effect of competition. For example, non-GM dealerships may have a stronger incentive to enter markets where customer loyalty to GM brands is lower. The number of dealerships in a market becomes a proxy of consumer's lack of loyalty for GM, which could have a positive association with the service level chosen by GM dealers. ${ }^{29}$ Given the demographic controls included in $W$, we believe it is unlikely that unobserved consumer characteristics that affect service level are correlated with market population. Hence, the IV estimates should be consistent. Nevertheless, we provide additional results following a different identification strategy which corroborate our findings.

In equation (6) we use the number of dealerships in a market as a measure of competition. We argue, due to the demand attraction and retention effects, that dealerships raise their service level when they face more intense competition to prevent losing customers to rival stores. If so, then the

allow matching based only on commonly repeated words, such as town or make names. For example, two dealers located in Swainsboro, GA with names "Swainsboro Chevrolet" and "Swainsboro Toyota" are not considered to be jointly owned.

${ }^{28}$ Since we do not observe the inventory of dealers other than GM, we do not know which brands are sold at non-GM dealerships. Edmunds.com provides information on the brands offered by dealers, which we used to construct the measure of competition based on brands.

${ }^{29}$ For example, suppose there exists some consumer characteristic describing loyalty for GM brands which is observed by firms and unobserved by the econometrician. This characteristic must be particular to a subset of markets because we control (via brand dummies) for the overall preference for GM brands. Based on this characteristic, Ford dealers are attracted to markets where loyalty for GM is low. GM dealerships raise their service level in these markets because of the presence of this characteristic, not per se because of the presence of the Ford dealership. 
effect of entry on service level should depend not only on the number of dealerships in a market but also on the number and type of products they offer. An entrant that offers more models which are close substitutes to the products offered by the incumbents should trigger a larger increase in the service level. In fact, Cachon and Olivares (2006) show that the aggregate inventory of a model tends to increase with the number of models offered in the same segment.

To validate our conjecture, we estimate equation (6) using the number of models offered by rival dealerships as a measure of competition. Following the literature of spatial competition (e.g. Seim $\underline{(2006)})$, we define different bands where the products offered by rival dealerships can be located. These bands define a measure of "distance" between product $b$ and products offered by rivals. The definition of the bands is based on a market segmentation commonly used in the auto industry. While these definitions can be subjective, we feel they work reasonably well to capture the degree of similarity across products in this industry. We conjecture that the number of products in closer bands should have a higher impact on the service level than products located in the outer bands. On the contrary, if the association between service level and market structure is driven by unobserved customer loyalty for GM, then products in all bands should have a similar positive association, because customer loyalty for GM would affect entry in all bands evenly. Therefore, this model is useful to determine whether unobserved factors related to customer loyalty for GM could be confounding the competition effect estimated in Table 5.

Let $\Omega$ be the set of all models offered in model-year 2007. For a given product $b$, we define a partition $\left\{\Omega_{b}^{1} \ldots \Omega_{b}^{K}\right\}$ of the set of products $\Omega$ and refer to $\Omega_{b}^{k}$ as the $k^{t h}$ band of product $b$. Bands are defined so that their distance to product $b$ is increasing in $k$. Let $C_{r b}^{k}$ be the number of models in band $\Omega_{b}^{k}$ offered by the rivals of dealership $r$. The number of models offered is calculated based on the brands carried by each rival dealership and the list of models offered by each brand ${ }^{30}$. We included dealerships of all manufacturers (not just the six included in the previous estimation). Define the column vector $C_{r b}=\left(C_{r b}^{1} \ldots C_{r b}^{K}\right)^{\prime}$ and the row vector of parameters $\psi=\left(\psi^{1} \ldots \psi^{K}\right)$. The parameter $\psi^{k}$ measures the average effect of adding a model in the $k^{\text {th }}$ band to the assortment of a rival dealership in the market.

We estimate the following linear model (6):

$$
y_{r b}=\beta X_{r b}+\psi C_{r b}+\gamma_{d} W_{m(r)}^{d}+\epsilon_{r b}
$$

\footnotetext{
${ }^{30}$ We do not know the actual number of models offered since we do not observe inventory of dealerships other than GM.
} 
were $y_{r b}, X_{r b}$ are defined as before and $W_{m(r)}^{d}$ includes demographics (it does not include measures of competition). This model is different from (6) because the service level effect, which in (9) is captured by $\psi C_{r b}$, depends not only on the number of dealerships in the market but also the number and type of models they offer. Two GM dealers located in the same local market carrying different assortments (e.g. a GMC dealers and a Chevrolet dealer) therefore face different levels of competition. We define product bands based on Ward's model segmentation, which classifies models into 26 segments based on three dimensions: vehicle class (e.g. standard car, luxury car, sport utility vehicle), size and price.

For our analysis, we focus on groups of products for which at least three product bands can be reasonably defined. We chose small and medium sized standard cars (hereon SM cars, which exclude luxury and large cars) and light-trucks (hereon Trucks, which include SUV, CUV and mini-van) ${ }^{31}$. We defined bands for the segments in each of these two groups and ran two separate regressions. The dependent variable is the logarithm of the average inventory level of models in a specific model segment offered by each dealership. For example, for the SM car regression, inventory of "Lower Small Car" and "Upper Middle Car" of a specific dealership is counted as two different observations. For SM cars, four bands were defined. The first band includes standard cars which have similar size or price $(B(P R I C E, S I Z E))$. The second band includes all other standard cars $(B(S T D C A R))$. The third and fourth band includes luxury cars and light-trucks, respectively $(B(A N Y C A R)$ and $B(O T H E R))^{32}$. For Trucks, we defined three bands. The first band includes vehicles within the same class with similar size or price $(B(P R I C E, S I Z E))$. For example, if $b=$ "Middle SUV", band 1 includes vehicles in the segments "Middle Luxury SUV" and "Large SUV" but not "Large Luxury SUV" or "Middle CUV". Band 2 includes all other trucks $(B(T R U C K))$, and band 3 all cars (B(OTHER)).

Table 8 summarizes the OLS estimation results of model (9) for SM cars and Trucks. The results show that the number of vehicles in the first band has a positive effect on the service level, and the marginal effect is decreasing in the number of vehicles. The number of vehicles in the outer bands have no significant effect on the service level (conditional on the number of models in the first band). The results are similar in sign and magnitude across the SM cars and Truck regressions, but the statistical significance of the Truck results is smaller.

\footnotetext{
${ }^{31}$ Full-sized vans and pickups are excluded because we could not obtain inventory data on them. We excluded large and luxury cars because bands for these types of vehicles could not be reasonably defined.

${ }^{32} \mathrm{~A}$ regression that merges the $3 \mathrm{rd}$ and 4 th brand obtains similar results.
} 
To compare the magnitude of the service level effect between this product competition model and our initial "number-of-dealerships" competition model (equation (6)), we estimate the implied elasticities of each model. For the SM car and Truck product competition models, increasing the number of products in the first band by one standard deviation at the mean increases inventory by $15 \%$ and $6 \%$, respectively. This is similar to the marginal effect obtained in the dealership competition model estimated in Table 5 (12.5\%), suggesting that they are capturing a similar effect: the impact of competition on service level.

Model (9) is estimated with OLS, which can produce biased estimates because $C_{r b}$ is endogenous. The concern is that idiosyncratic consumer tastes for specific type of vehicles will affect product line decisions of dealers and their service levels at the same time, confounding the causal effect of $C_{r b}$. Unfortunately, we do not have instruments to correct for the endogeneity of product line decisions. Due to this, we believe that our estimation results using IV (reported in Table 5) are more robust to a potential endogeneity bias. Nevertheless, the results from Table 8 provide further support on the causal effect of competition: it is hard to find a confounder that biases the estimates of the service level effect in all the models we consider. In short, the estimated effect of competition on service level is robust to different specifications and identification strategies.

To summarize, our empirical results can be interpreted as follows. First, the number of vehicles offered by rivals has a positive effect on the service level of the products offered by a dealership. Second, most of the effect of competition on service level is captured by products which are close substitutes, i.e., a dealer does not respond to the entry of another dealer selling products in different segments but the incumbent dealer does increase its service level in response to the entry of another dealer who sells products in similar segments to the incumbent dealer. Third, there is a saturation effect: the first close substitutes have a large impact on service level, but the effect becomes smaller as more products enter the first band. Overall, these empirical results provide good support for our conjecture that the intensity of inventory competition depends on the number and type of products offered in a market. This pattern is unlikely to be driven by unobserved market characteristics affecting service level. 


\section{Economic significance of local competition on dealership inven- tory}

There is concern in the U.S. automobile industry that the domestic manufacturers have too many dealerships because (a) their dealership networks were established in the first half of the century when the country was less urbanized and (b) restrictive franchise laws impose significant costs for closing dealerships involuntarily (Rechtin and Wilson (2006)). Indeed, GM paid more than one billion dollars to Oldsmobile dealers to close that brand, see Welch (2006)) Thus, it is of interest to evaluate the potential impact of reducing the number of dealerships. This should have two effects on the remaining dealerships: (1) their sales will increase (they will capture some of the sales from the closed dealership) and (2) they will reduce their service level (because they face less competition). According to our estimates, both effects reduce days-of-supply (inventory relative to sales) which reduces inventory costs: inventory that turns over more quickly is less costly to hold. In this section, we evaluate the relative magnitude of these two effects.

We used the estimates of Table 5, column 4, to measure the effect of closing some of GM's dealerships. ${ }^{33}$ As in our estimation, we selected markets with eight or fewer dealerships. Among these markets there are three or fewer GM dealerships. To evaluate the impact of reducing the number of dealerships, we assumed in each market all GM dealerships are closed except the one with the highest sales. If the dealership has multiple brands, then all of the brands are closed. Furthermore, we assume all other dealerships remain (and none are added). The change in the remaining GM dealer's inventory depends on the number of sales it captures from the closed GM dealerships. Assuming all sales from the closed dealerships are lost provides a lower bound whereas assuming all of those sales are captured by the remaining dealer provides an upper bound of the sales effect. Thus, the lower bound provides the inventory reduction due only to the service level effect and the upper bound combines the service level effect with the maximum sales effect. Table 9 summarizes the results, where we report days-of-supply because we are interested in the potential change in inventory costs.

We find that the remaining dealer's days-of-supply would decrease by 21 to 39 days: the 21 day reduction represents the service-level effect and the difference, 18 days, represents the sales effect. Hence, we find that the service level effect is of comparable magnitude to the sales effect. These results indicate that GM would carry less inventory (as measured by days-of-supply) if it

\footnotetext{
${ }^{33}$ The OLS estimates are more precise than the IV estimates and yield a more conservative reduction.
} 
were to close dealerships in our sample of its network. We emphasize that these results pertain to our sample because, in part, of the non-linear relationship between the number of dealerships and the service level effect. For example, closing one of two GM dealership in a market with 6 other (non-GM) dealerships has a different effect than closing one of two GM dealership in a market with only 1 other (non-GM) dealership. Therefore, even if our parameter estimates apply to all GM markets, the magnitude of these effects depend on the particular composition of each market. It follows that is safest to interpret these results exclusively for the isolated markets we consider.

It is also important to be aware that we have not attempted to make an economic justification for closing dealerships. Our results suggest that doing so will have a substantial impact on the inventory carried by the remaining dealerships, but we have not quantified the sales impact, nor can we compare the inventory holding cost savings with the potential profit impact of changing sales.

\section{Conclusion}

We develop an econometric model to estimate the effect of competition on inventory holdings. We identify two drivers of inventory holdings: a sales effect and a service level effect. We find that the sales effect reflects strong economies of scale in managing inventory - increasing a dealer's sales reduces the dealer's inventory when measured in terms of days-of-supply.

We are particularly interested in the impact of local competition on service levels (buffer inventory held by dealerships conditional on sales). Theory is ambiguous on this point - some models predict increased competition increases inventory, others predict a neutral relationship and yet others predict that increased competition decreases inventory. In the context of the dealerships in the automobile industry, we find that competition increases service levels. If we consider service level more generally as a form of service quality, this result is similar to the findings of Berry and Waldfogel (2001)(competition increases quality provided by restaurants) and Mazzeo (2003) (competition in airline routes reduces flight delays).

While we find that competition increases inventory in the auto industry, we also find that the marginal effect of competition is decreasing: the first entrant into a market with one established dealer causes a $14 \%$ increase in inventory whereas entry beyond the seventh dealership has no positive effect on inventory (conditional on sales). We provide additional empirical evidence showing that the service level of products depends on the number of close substitutes offered by 
rivals, but is insensitive to the number of dissimilar products.

Our findings suggest that inventory may vary across automobile brands in part because auto brands vary in their dealership structures. As the dealership network becomes more dense there are two reinforcing effects on inventory. One, if sales per dealership declines as the number of dealerships increases (which is plausible), then the presence of economies of scales with respect to sales suggests that inventory, measured in days-of-supply, will increase. Second, an increase in the density of dealerships increases competition (i.e., more dealerships per market), which also increases inventory via higher service levels. Thus, when comparing two automobile distribution networks, we expect (all else being equal) the one with the greater number of dealerships to carry more inventory.

It is of interest to confirm whether our results hold for dealerships in urban markets, for other automobile manufacturers, and in other retail industries. For example, in other retail industries it could be possible that additional competition reduces margins significantly, and such margin effect could dominate any demand retention or attraction effects. In those cases, in contrast to our results, increased competition would lead to lower service levels. Finally, given the recent turmoil in the automobile industry, it is important to confirm that the dynamics in this industry have not changed, at least with respect to competition and services levels. 


\section{Appendix}

\subsection{Properties of $K(z)$ function}

Let $D$ be a normally distributed random variable with mean $\mu$ and standard deviation $\sigma$. Define $Q=\mu+z \sigma$ and $S=\min \{Q, D\}$. Define $Y \equiv Q-D$ and $V(\cdot)$ as the variance operator. Using a result for the normal distribution truncated at zero (see \cite\{olsen1980\}):

$$
\begin{aligned}
V(D \mid D<Q) & =V(Y \mid Y>0) \\
& =\sigma^{2}\{1+\lambda(z)[-z-\lambda(z)]\}
\end{aligned}
$$

where $\lambda(z)=\phi(z) / \Phi(z)$ is the hazard rate. The variance of sales $V(S)$ can be expressed as

$$
\begin{aligned}
V(S) & =V(S \mid D \geq Q) \operatorname{Pr}(D \geq Q)+V(S \mid D<Q) \operatorname{Pr}(D<Q) \\
& =\sigma^{2}\{\Phi(z)-\phi(z)[z+\lambda(z)]\}
\end{aligned}
$$

where $\sigma^{2}=V(D)$ and (11) follows from (10).

Begin with (1) and substitute the loss function for the standard normal, $L(z)=\phi(z)-$ $z(1-\Phi(z))$, and $\sigma$ derived from (11) to yield

$$
I=\sigma_{s} K(z)
$$

where $\sigma_{s}=V(S)^{1 / 2}$ and

$$
K(z)=(z \Phi(z)+\phi(z))\{\Phi(z)-\phi(z)[z+\lambda(z)]\}^{-1 / 2}
$$

Next, we wish to show that $K(z)$ is increasing in $z$. Denote $f_{1}=(z \Phi(z)+\phi(z))$ and $f_{2}(z)=$ $\Phi(z)-\phi(z)[z+\lambda(z)]$. Note that $f_{1}^{\prime}=\Phi(z)$ and that $f_{2}(z) \geq 0$ (otherwise, $V(S)$ could be negative). It follows that

$$
\begin{aligned}
\operatorname{sign}\left\{K^{\prime}(z)\right\} & =\operatorname{sign}\left\{\Phi(z) \cdot f_{2}(z)-\frac{1}{2} f_{2}^{\prime}(z) f_{1}(z)\right\} \\
& =\operatorname{sign}\left\{f_{2}(z)-\frac{1}{2} \phi(z)(z+\lambda(z))^{3}\right\} \\
& =\operatorname{sign}\left\{\Phi(z)-\phi(z)[z+\lambda(z)] \cdot\left[1-\frac{1}{2}(z+\lambda(z))^{2}\right]\right\}
\end{aligned}
$$

which is positive given that $f_{2}(z) \geq 0$. 


\subsection{GMM Estimation}

Our estimation can be viewed as a special case of multiple equation GMM (see Hayashi (2000), Chapter 4 for a general treatment of multiple equation GMM). We redefine our notation to fit our model into this framework. Define $\epsilon_{1 i}=\nu_{i}, \epsilon_{2 i}=\varepsilon_{i}, y_{1 i}=\dot{y}_{i}, y_{2 i}=y_{i}$ and the column vectors $U_{1 i}=\left(\dot{X}_{i}, \overrightarrow{0}_{k_{\gamma}}\right), U_{2 i}=\left(X_{i}, W_{m(i)}\right)$, where $\overrightarrow{0}_{k_{\gamma}}$ is a column vector of zeros of dimension $k_{\gamma}$.We estimate the following moment conditions:

$$
\begin{aligned}
& E\left(Z_{1 i} \epsilon_{1 i}\right)=0 \\
& E\left(Z_{2 i} \epsilon_{2 i}\right)=0
\end{aligned}
$$

where $Z_{1 i}$ and $Z_{2 i}$ are vectors of exogenous instruments. $Z_{2 i}$ includes measures of current and past market population (described in section 3.3) and all demographics included in $W_{m(i)}$. $Z_{1 i}$ includes $\dot{X}_{i}$ and all the covariates included in $Z_{2 i}$. Let $k_{p}=\operatorname{dim}\left(Z_{p i}\right)$ for $p=1,2, k_{\beta}=\operatorname{dim}(\beta)$ and $k_{\gamma}=\operatorname{dim}(\gamma)$ be the dimensions of the exogenous instruments and the vector parameters $\beta$ and $\gamma$. The error terms are given by:

$$
\begin{aligned}
& \epsilon_{1 i}(\theta)=y_{1 i}-\theta U_{1 i} \\
& \epsilon_{2 i}(\theta)=y_{2 i}-\theta U_{2 i}
\end{aligned}
$$

Define the stacked column vector

$$
g_{i}(\theta)=\left[\begin{array}{c}
Z_{1 i} \epsilon_{1 i}(\theta) \\
Z_{2 i} \epsilon_{2 i}(\theta)
\end{array}\right]
$$

The sample counterpart of the moment conditions (12) and (13) is given by $g(\theta)=\frac{1}{n} \sum_{i=1}^{n} g_{i}(\theta)$, where $n$ is the number of observations.

If $k_{1}+k_{2}=k_{\beta}+k_{\gamma}$ the model is said to be "just identified"; in this case, $\theta$ can be chosen to make $g(\theta)=\overrightarrow{0}$. If $k_{1}+k_{2}<k_{\beta}+k_{\gamma}$, the model is not identified: there are infinite values of $\theta$ that yield $g(\theta)=\overrightarrow{0}$. If $k_{1}+k_{2}>k_{\beta}+k_{\gamma}$, which is our case, the model is said to be over-identified and $\theta$ is chosen to solve the quadratic form

$$
\hat{\theta}(H)=\arg \min _{\theta} g(\theta)^{\prime} H g(\theta)
$$

where $H$ is any square positive-definite matrix of dimension $k_{1}+k_{2} . H$ is referred to as the weighting matrix, and $\theta(H)$ is consistent for any choice of $H$. Because $g(\theta)$ is linear in $\theta,(14)$ can be solved analytically:

$$
\hat{\theta}(H)=\left(S_{z u}^{\prime} H S_{z}\right)^{-1} S_{z u} H s_{z y}
$$


where

$$
s_{z y}=\left[\begin{array}{c}
\sum_{i=1}^{n} Z_{1 i} y_{1 i} \\
\sum_{i=1}^{n} Z_{2 i} y_{2 i}
\end{array}\right], \text { and } S_{z u}=\left[\begin{array}{c}
\sum_{i=1}^{n} Z_{1 i} U_{1 i}^{\prime} \\
\sum_{i=1}^{n} Z_{2 i} U_{2 i}^{\prime}
\end{array}\right]
$$

There is a choice of $H$ that makes $\theta(H)$ efficient (it minimizes its asymptotic standard error). Standard results of GMM show that efficiency is maximized by choosing $H$ as the inverse of $S=$ $E\left[g_{i} g_{i}^{\prime}\right]$. The computation of this efficient weighting matrix requires approximating the expectation $E\left[g_{i}^{\prime} g_{i}\right]$ whose sample counterpart depends on $\theta$. Hence, one needs to know $\theta$ before computing an estimate of $S$. GMM operates in two steps: in the first step, one can use any weighting matrix $H$ to obtain a consistent estimate of $\theta$; in the second step, we use the estimated $\hat{\theta}$ to compute a consistent estimate of $S$,

$$
\hat{S}=\frac{1}{n} \sum_{i=1}^{n} g_{i}(\hat{\theta})^{\prime} g_{i}(\hat{\theta})
$$

and then re-estimate $\theta$ by solving (14) using $H=\hat{S}^{-1}$. In our case, we use the consistent estimate of $\theta$ provided by the two-step method described in section 2 to estimate $\hat{S}$. Denoting $\theta_{0}$ the true parameter and $\theta^{*}$ the efficient GMM estimator, the asymptotic variance is given by:

$$
\begin{aligned}
\operatorname{Avar}\left(\theta^{*}\right) & =\operatorname{Var}\left(\sqrt{n}\left(\theta^{*}-\theta_{0}\right)\right) \\
& =\left(S_{z u}^{\prime} \hat{S}^{-1} S_{z u}\right)^{-1}
\end{aligned}
$$

The estimator $\theta^{*}$ has a multivariate normal distribution with mean $\theta_{0}$ and covariance matrix $n^{-1} \operatorname{Avar}\left(\theta^{*}\right)$. 


\section{References}

Agarwal, M.K., B.T. Ratchford. 1980. Estimating Demand Functions for Product Characteristics: The Case of Automobiles. The Journal of Consumer Research 7(3) 249-262.

Alexander, Peter. 1997. Product variety and market structure: A new measure and a simple test. Journal of Economic Behavior and Organization 32 207-214.

Amihud, Yakov, Haim Mendelson. 1989. Inventory behavior and market power. International Journal of Industrial Organization 7 269-280.

Anupindi, Ravi, Yehuda Bassok. 1992. Centralization of stocks: Retailers vs. manufacturer. Management Science 45(2) 178-188.

Balachander, Subramanian, Peter H. Farquhar. 1994. Gaining more by stocking less: A competitive analysis of product availablility. Marketing Science 13(1) 3-22.

Bernstein, Fernando, Awi Federgruen. 2005. Descentralized supply chains with competing retailers under demand uncertainty. Management Science 51(1) 18-29.

Berry, S., J. Levinsohn, A. Pakes. 2004. Differentiated Products Demand Systems from a Combination of Micro and Macro Data: The New Car Market. Journal of Political Economy 112(1) $\underline{68-105 .}$

Berry, Steve, Joel Waldfogel. 2001. Do mergers increase product variety? Evidence from radio broadcasting. The Quarterly Journal of Economics 116(3) 1009-25.

Berry, Steven, Joel Waldfogel. 2003. Product Quality and Market Size. NBER working paper.

Bresnahan, Timothy, Peter Reiss. 1990. Entry in monopoly markets. The Review of Economic Studies 57(4) 531-553.

Bresnahan, Timothy, Peter Reiss. 1991. Entry and competition in concentrated markets. The Journal of Political Economy 99(5) 977-1099.

Cachon, Gerard. 2003. Supply chain coordination with contracts. Handbooks in Operations Research and Management Science: Supply Chain Management, S. Graves and T. de Kok. 11:229339. 
Cachon, Gerard P., Marcelo Olivares. 2006. Drivers of finished goods inventory performance in the U.S. automobile industry. Available at SSRN: http://ssrn.com/abstract=980728.

Cachon, Gerard P., Christian Terwiesch, Yi Xu. 2006. The impact of consumer search, firm entry and competition on assortment and pricing. Marketing Science Forthcoming.

Cohen, Andrew, Michael Mazzeo. 2004. Competition, Product Differentiation and Quality Provision: An Empirical Equilibrium Analysis of Bank Branching Decisions. Tech. rep., Federal Reserve Board, Washington D.C.

Dana, James. 2001. Competition in price and availability when availability is unobservable. $R A N D$ Journal of Economics 32(3) 497-513.

Dana, James, Nicholas Petruzzi. 2001. Note: The newsvendor model with endogenous demand. Management Science 47(11) 1488-97.

Daugherty, Andrew, Jennifer Reinganum. 1991. Endogenous availability in search equilibrium. Rand Journal of Economics 22(2) 287-306.

Deneckere, Raymond, James Peck. 1995. Competition over price and service rate when demand is stochastic: A strategic analysis. RAND Journal of Economics 26(1) 148-162.

Dranove, David, Mark Shanley, Carol Simon. 1992. Is hospital competition wasteful? RAND Journal of Economics 23(2).

Dudey, Marc. 1990. Competition by choice: The effect of consumer search on firm location decisions. American Economic Review 80(5) 1092-104.

Eaton, Curtis, Richard G. Lipsey. 1982. An economic theory of central places. The Economic Journal 56-72.

Ellickson, Paul B. 2007. Does Sutton apply to supermarkets? Rand Journal of Economics 38(1) $43-59$.

Gaur, Vishal, Marshall L. Fisher, Ananth Raman. 2005a. An econometric analysis of inventory turnover performance in retail services. Management Science 51(2) 181-194.

Gaur, Vishal, Saravanan Kesavan, Ananth Raman, Marshall Fisher. 2005b. Estimating demand uncertainty using judgemental forecasts. Working paper, http://pages.stern.nyu.edu/ vgaur/. 
Gerchak, Yigal, Yunzeng Wang. 1994. Periodic-review inventory models with inventory-level dependent demand. Naval Research Logistics 41 99-116.

Hayashi, Fumio. 2000. Econometrics. Princeton University Press, Princeton, New Jersey.

Hendricks, Kevin B., Vinod R. Singhal. 2005. Association between supply chain glitches and operating performance. Management Science 51(5) 695-711.

Lippman, Steven, Kevin McCardle. 1997. The competitive newsboy. Operations Research 45 54-65.

Mahajan, Siddarth, Garrett van Ryzin. 2001. Inventory competition under dynamic consumer choice. Operations Research 49(5) 646-657.

Marx, Thomas G. 1985. The development of the franchise distribution system in the U.S. automobile industry. The Business History Review 59 465-474.

Mazzeo, M.J. 2003. Competition and service quality in the US airline industry. Review of Industrial Organization 22(4) 275-296.

Narus, James A., James C. Anderson. 1996. Rethinking distribution. Harvard Business Review $112-120$.

Netessine, Serguei, Nils Rudi. 2003. Centralized and competitive inventory models with demand substitution. Operations Research 51(2).

Rajagopalan, S. 2005. Determinants of inventory levels at U.S. retailers: An empirical study. Working paper, University of Southern California.

Rechtin, Mark, Amy Wilson. 2006. Thinning the herd. Automotive News 81 82-84.

Rudi, Nils, Sandeep Kapur, David F. Pyke. 2001. A two-location inventory model with transshipment and local decision making. Management Science 47(12) 1668-80.

Rumyantsev, Serguei, Serguei Netessine. 2007. What Can Be Learned from Classical Inventory Models? A Cross-Industry Exploratory Investigation. Manufacturing $\mathscr{E}$ Service Operations Management $\mathbf{9}(4) 409$.

Seim, Katja. 2006. An empirical model of firm entry with endogenous product-type choices. $R A N D$ Journal of Economics Forthcoming. 
Smith, Richard L. 1982. Franchise regulation: An economic analysis of state restrictions on automobile distribution. Journal of Law and Economics 25(1) 125-157.

Stahl, Konrad. 1982. Differentiated products, consumer search, and locational oligopoly. Journal of Industrial Economics 31 97-113.

van Ryzin, Garrett, Siddarth Mahajan. 1999. On the relationship between inventory costs and variety benefits in retail assortments. Management Science 45(11) 1496-1509.

Watson, Randall. 2004. Product variety and competition in the retail market for eyeglasses. Working paper, University of Texas at Austin.

Watson, Randall. 2006. Search, availability, and competition in product ranges. Working paper, Department of Economics, University of Texas at Austin.

Welch, David. 2006. The other club battering GM. Businessweek 3974(38).

Wolinsky, Asher. 1983. Retail trade concentration due to consumers' imperfect information. Bell Journal of Economics 14(14) 275-82.

Wooldridge, Jeffrey. 2002. Econometric Analysis of Cross Section and Panel Data. MIT Press, Cambridge, Massachusetts.

Wu, Owen Q., Hong Chen, Murray Z. Frank. 2005. What actually happened to the inventories of American companies between 1981 and 2000. Management Science 51(7) 1015-1031.

Zipkin, Paul. 2000. Foundations of Inventory Management. McGraw-Hill. 
Table 1: Inventory holdings of General Motor brand dealerships in our data sample (from 8/15/06 to 2/15/07)

\begin{tabular}{lrrrrrrr}
\hline \hline & Buick & Cadillac Chevrolet & GMC & Pontiac & Saturn & All \\
\hline Number of dealers & 134 & 109 & 170 & 101 & 134 & 6 & 654 \\
Average inventory per dealer & 12 & 12 & 44 & 17 & 16 & 93 & 23 \\
Mean days-of-supply & 151 & 151 & 133 & 130 & 197 & 118 & 152 \\
Std. deviation of days-of-supply & 80 & 83 & 43 & 59 & 91 & 32 & 76 \\
\hline
\end{tabular}

Table 2: Market selection criteria. A UA with population indicated in column 1 is chosen if it meets the criteria in columns 2-5

\begin{tabular}{lrrrr}
\hline \hline $\begin{array}{l}\text { Population in UA } \\
\text { (thousands) }\end{array}$ & $\begin{array}{r}\text { Minimum distance (in miles) to a UA with the following } \\
\text { populations, } P\end{array}$ \\
& $P>10$ & $P>25$ & $P>50$ & $P>100$ \\
\hline$[0,25]$ & 30 & 30 & 50 & 50 \\
{$[25,50]$} & -- & 30 & 50 & 50 \\
{$[50,100]$} & -- & -- & 30 & 50 \\
{$[100,150]$} & -- & -- & -- & 50 \\
\hline
\end{tabular}

Table 3 - Market composition. The last three columns show the percent of markets with at least one dealership of non-GM domestic manufacturers, Japanese manufacturers and a second GM dealership, respectively.

\begin{tabular}{rrrrrr}
\hline \hline & & & \multicolumn{4}{c}{$\%$ of markets with dealers } \\
\cline { 4 - 6 } \# of & $\begin{array}{r}\text { \# of } \\
\text { markets }\end{array}$ & $\begin{array}{r}\text { Median } \\
\text { population }\end{array}$ & $\begin{array}{r}\text { non-GM } \\
\text { domestic }\end{array}$ & Japanese & 2nd GM \\
\hline 1 & 10 & 3.4 & $0 \%$ & $0 \%$ & $0 \%$ \\
2 & 24 & 6.2 & $88 \%$ & $8 \%$ & $4 \%$ \\
3 & 41 & 9.8 & $100 \%$ & $5 \%$ & $2 \%$ \\
4 & 27 & 14.3 & $100 \%$ & $48 \%$ & $41 \%$ \\
5 & 24 & 20.8 & $100 \%$ & $83 \%$ & $50 \%$ \\
6 & 21 & 38.2 & $100 \%$ & $100 \%$ & $43 \%$ \\
7 & 15 & 38.3 & $100 \%$ & $100 \%$ & $67 \%$ \\
8 & 20 & 57.4 & $100 \%$ & $100 \%$ & $95 \%$ \\
9 & 11 & 74.1 & $100 \%$ & $100 \%$ & $100 \%$ \\
10 & 12 & 68.2 & $100 \%$ & $100 \%$ & $100 \%$ \\
11 & 10 & 75.4 & $100 \%$ & $100 \%$ & $100 \%$ \\
12 & 3 & 100.3 & $100 \%$ & $100 \%$ & $100 \%$ \\
13 & 6 & 122.0 & $100 \%$ & $100 \%$ & $100 \%$ \\
14 & 1 & 105.4 & $100 \%$ & $100 \%$ & $100 \%$ \\
15 & 1 & 123.0 & $100 \%$ & $100 \%$ & $100 \%$ \\
\hline
\end{tabular}


Table 4: Summary statistics and correlation matrix.

\begin{tabular}{lrrrrrrrrrrr}
\hline \hline & & & & \multicolumn{1}{c}{ Correlations } \\
\multicolumn{1}{l}{ Variable } & Mean & Std. Dev. & Min & Max & $(1)$ & $(2)$ & $(3)$ & $(4)$ & (5) & (6) \\
\hline (1) logINV & 2.62 & 1.01 & 0.13 & 5.06 & 1.00 & & & & & \\
(2) logSALES & 2.92 & 1.05 & 0.00 & 5.75 & 0.91 & 1.00 & & & & \\
(3) ND & 4.68 & 2.07 & 1.00 & 8.00 & 0.47 & 0.45 & 1.00 & & & \\
(4) NGM & 1.50 & 0.63 & 1.00 & 3.00 & 0.38 & 0.37 & 0.68 & 1.00 & & \\
(5) OUTSIDE & 0.94 & 0.56 & 0.02 & 3.42 & -0.14 & -0.16 & -0.15 & -0.18 & 1.00 & \\
(6) NBRAND & 3.41 & 1.25 & 1.00 & 5.00 & -0.30 & -0.31 & -0.34 & -0.51 & 0.15 & 1.00 \\
(7) TRANSF & 0.07 & 0.09 & 0.00 & 0.57 & -0.14 & -0.01 & -0.09 & -0.05 & -0.02 & 0.05 \\
\hline
\end{tabular}

Table 5 - Main estimation results. Dependent variable is logINV. Demographic variables and dummies for brand, region and ALLSTATE are not shown. Column (1) shows the results from the $1^{\text {st }}$ step of the two step method; columns (2)-(4) shows the estimates from the $2^{\text {nd }}$ step. Column (3) uses IVs to instrument for ND and NDSQ. Column (5) shows the joint estimation using GMM. Standard errors shown in parenthesis. ** and * indicate significance at the $1 \%$ and $5 \%$. Robust standard errors are reported for column (1).

\begin{tabular}{|c|c|c|c|c|c|}
\hline & $\begin{array}{l}\text { Step } 1 \\
\text { (1) } \\
\text { OLS }\end{array}$ & $\begin{array}{l}(2) \\
\text { OLS }\end{array}$ & $\begin{array}{l}\text { (3) } \\
\text { IV }\end{array}$ & $\begin{array}{l}\text { (4) } \\
\text { OLS }\end{array}$ & $\begin{array}{l}\text { Joint } \\
(5) \\
\text { GMM }\end{array}$ \\
\hline logSALES & $\begin{array}{l}0.640^{\star \star} \\
(0.027)\end{array}$ & & & & $\begin{array}{l}0.675^{\star \star} \\
(0.022)\end{array}$ \\
\hline NBRAND & $\begin{array}{l}0.035 \\
(0.023)\end{array}$ & & & & $\begin{array}{l}-0.011 \\
(0.020)\end{array}$ \\
\hline TRANSF & $\begin{array}{l}-0.790^{\star \star} \\
(0.228)\end{array}$ & & & & $\begin{array}{l}-0.82^{\star \star} \\
(0.156)\end{array}$ \\
\hline$N D$ & & $\left(0.159^{\star \star}\right.$ & $\begin{array}{l}0.333^{\star} \\
(0.133)\end{array}$ & $\begin{array}{l}0.161^{\star \star} \\
(0.038)\end{array}$ & $\begin{array}{l}0.387^{\star \star} \\
(0.100)\end{array}$ \\
\hline NDSQ & & $\begin{array}{l}-0.009^{*} \\
(0.004)\end{array}$ & $\begin{array}{l}-0.023 \\
(0.014)\end{array}$ & $\begin{array}{l}-0.012^{\star \star} \\
(0.004)\end{array}$ & $\begin{array}{l}-0.031^{\star *} \\
(0.011)\end{array}$ \\
\hline$N G M$ & & & & $\begin{array}{l}0.133^{\star \star} \\
(0.035)\end{array}$ & \\
\hline OUTSIDE & & $\begin{array}{l}-0.070^{*} \\
(0.031)\end{array}$ & $\begin{array}{l}-0.036 \\
(0.033)\end{array}$ & $\begin{array}{l}-0.070^{\star} \\
(0.031)\end{array}$ & $\begin{array}{l}-0.028 \\
(0.024)\end{array}$ \\
\hline Observations & 654 & 649 & 649 & 649 & 649 \\
\hline R-squared & 0.84 & 0.26 & 0.22 & 0.27 & $\mathrm{n} / \mathrm{a}$ \\
\hline
\end{tabular}


Table 6: Days-of-supply for all dealer-brand pairs in isolated $(I N I M=1)$ and non-isolated $(I N I M=0)$ markets in seven states (CA,CO,FL,ME,NE,TX,WI)

\begin{tabular}{lll}
\hline \hline & $(1)$ & $(2)$ \\
INIM & $0.083^{\star \star}$ & 0.006 \\
& -0.031 & -0.03 \\
logPOP & & $-0.058^{\star \star}$ \\
& & -0.004 \\
Constant & $5.008^{\star \star}$ & $5.658^{\star \star}$ \\
& -0.05 & -0.073 \\
Observations & 2411 & 2411 \\
R-squared & 0.25 & 0.31 \\
\hline
\end{tabular}

Table 7: Days-of-supply evaluated from our data compared to data reported by Ward's Automotive

\begin{tabular}{lrrr}
\hline \hline & \multicolumn{2}{c}{ Days-of-supply } & \\
\cline { 2 - 3 } & & & $\begin{array}{r}\text { Necessary fleet sales to } \\
\text { add to our sales to match }\end{array}$ \\
Make & Our data from & 97 & $21 \%$ \\
Buick & 122 & 81 & $-2 \%$ \\
Cadillac & 79 & 81 & $22 \%$ \\
Chevrolet $\left({ }^{*}\right)$ & 104 & 92 & $25 \%$ \\
Pontiac-GMC $\left({ }^{*}\right)$ & 134 & 94 & $-1 \%$ \\
Saturn & 93 & & Ward's data \\
\hline
\end{tabular}

$(*)$ excludes Medium-duty pickups. 
Table 8 - Estimation results with the number of models as a measure of competition (equation (9)). Separate regressions were estimated for small- medium size cars (SM cars) and light trucks. N B(.) measures the number of models on each product band, and NSQ B(.) its square. All specifications include dummies for region, price and ALLSTATE, and demographic controls.

\begin{tabular}{|c|c|c|c|c|}
\hline & \multicolumn{2}{|c|}{ SM car } & \multicolumn{2}{|c|}{ Light Trucks } \\
\hline & (1) & $(2)$ & (3) & (4) \\
\hline LOGSALES & $\begin{array}{l}0.5711^{* *} \\
(0.028)\end{array}$ & $\begin{array}{l}0.5706^{\star *} \\
(0.028)\end{array}$ & $\begin{array}{l}0.7957^{* *} \\
(0.0241)\end{array}$ & $\begin{array}{l}0.7955^{\star *} \\
(0.0241)\end{array}$ \\
\hline TRANSF & $\begin{array}{l}-0.4064^{*} \\
(0.2037)\end{array}$ & $\begin{array}{l}-0.4273^{\star} \\
(0.2038)\end{array}$ & $\begin{array}{l}-0.3631 \\
(0.1886)\end{array}$ & $\begin{array}{l}-0.4030^{*} \\
(0.1894)\end{array}$ \\
\hline$N B(P R I C E, S I Z E)$ & $\begin{array}{l}0.0118^{\star} \\
(0.0057)\end{array}$ & $\begin{array}{l}0.0332^{\star \star} \\
(0.0118)\end{array}$ & $\begin{array}{l}0.0069 \\
(0.006)\end{array}$ & $\begin{array}{l}0.0304 \\
(0.019)\end{array}$ \\
\hline NSQ B(PRICE,SIZE) & & $\begin{array}{l}-0.0004^{*} \\
(0.0002)\end{array}$ & & $\begin{array}{l}-0.0006 \\
(0.0004)\end{array}$ \\
\hline$N B\left(S T D \_C A R\right)$ & $\begin{array}{l}-0.0125 \\
(0.0073)\end{array}$ & $\begin{array}{l}-0.0182 \\
(0.0154)\end{array}$ & & \\
\hline NSQ B(STD_CAR) & & $\begin{array}{l}0.0000 \\
(0.0002)\end{array}$ & & \\
\hline$N B\left(A N Y \_C A R\right)$ & $\begin{array}{l}-0.0143 \\
(0.0079)\end{array}$ & $\begin{array}{l}-0.0148 \\
(0.0129)\end{array}$ & & \\
\hline$N B(T R U C K)$ & & & $\begin{array}{l}-0.0066 \\
(0.0042)\end{array}$ & $\begin{array}{l}-0.0049 \\
(0.0092)\end{array}$ \\
\hline NSQ B(TRUCK) & & & & $\begin{array}{l}0.0000 \\
(0.0001)\end{array}$ \\
\hline$N B(O T H E R)$ & $\begin{array}{l}0.0004 \\
(0.0036)\end{array}$ & $\begin{array}{l}-0.0012 \\
(0.0037)\end{array}$ & $\begin{array}{l}0.0030 \\
(0.0048)\end{array}$ & $\begin{array}{l}0.0030 \\
(0.0049)\end{array}$ \\
\hline Observations & 775 & 775 & 712 & 712 \\
\hline$R$-squared & 0.6 & 0.6 & 0.69 & 0.69 \\
\hline
\end{tabular}

Table 9 - Comparison of sales and service level effects. The lower bound indicates the reduction in days-of-supply due to the service level effect of closing dealerships in the markets in our study; the upper bound is the reduction due to the service level and sales effects combined.

\begin{tabular}{ccccc}
\hline \hline & & & \multicolumn{2}{c}{ Reduction in days-of-supply } \\
\cline { 3 - 5 } \# dealers of closed & No. of obs. & Actual days-of-supply & Lower bound & Upper bound \\
\hline 1 & 115 & 144 & 21.9 & 38.4 \\
2 & 20 & 129 & 30.0 & 54.4 \\
Total & 142 & 140 & 21.8 & 39.4 \\
\hline
\end{tabular}


Figure 1: Location of dealerships in our sample

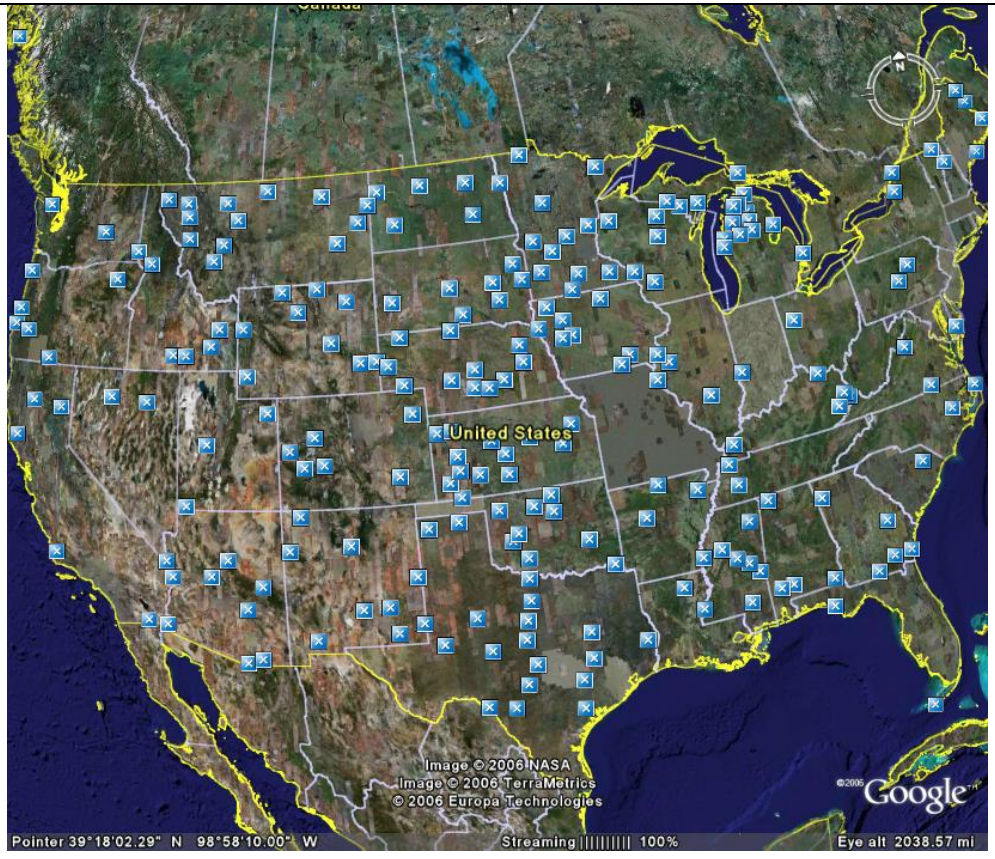

Figure 2 - Effect of competition on the targeted service level, measured as the change in inventory relative to a monopolist GM dealership. The curve shows the estimated effect using specification (2). + and - indicate upper and lower bounds on the 95\% confidence interval, respectively, for these estimates. Squares show the estimated effect using a flexible non-parametric function.

Service level effect of competition on inventory

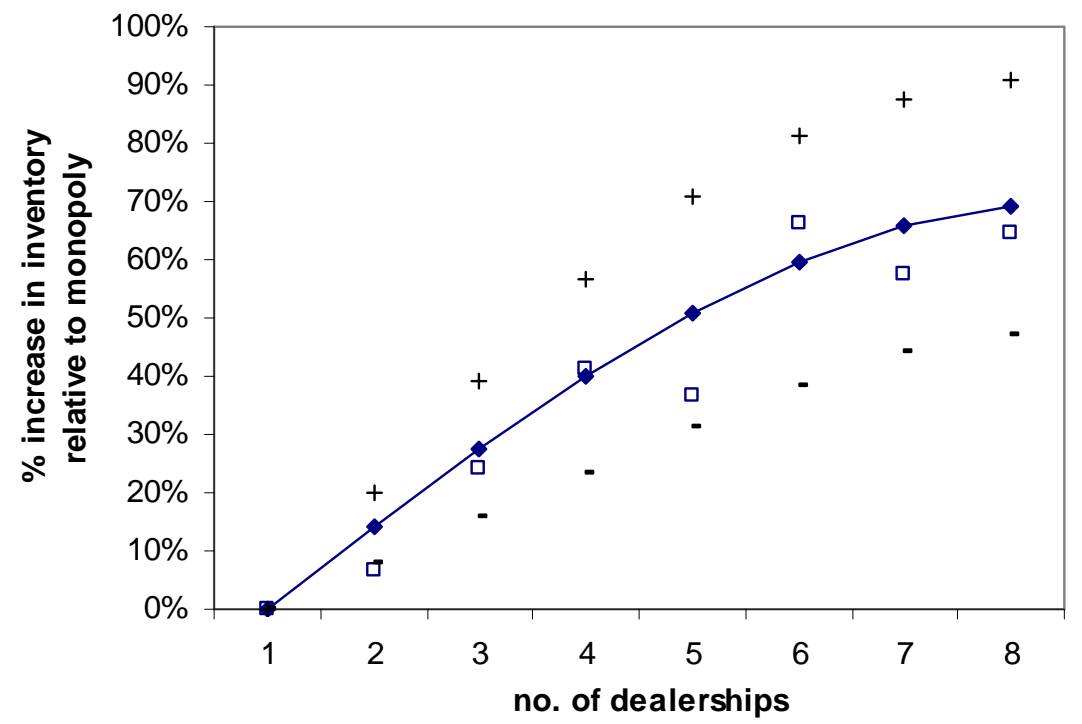

